\title{
Indicações Geográficas e desenvolvimento regional no Brasil: a atuação dos principais atores e suas metodologias de trabalho
}

\author{
Geographical Indications and regional development in Brazil: the performance \\ of the main actors and their methodologies of work

\begin{abstract}
Indications Géographiques et développement régional au Brésil: les
\end{abstract} \\ performances des principaux acteurs et leurs méthodologies de travail
}

\author{
Indicaciones Geográficas y desarrollo regional en Brasil: la actuación de los \\ principales actores y sus metodologías de trabajo
}

\author{
Valdinho Pellin ${ }^{1}$ \\ Recebido em 19/12/2017; revisado e aprovado em 21/05/2018; aceito em 06/06/2018 \\ DOI: http://dx.doi.org/ 10.20435/inter.v20i1.1792
}

\begin{abstract}
Resumo: O artigo procura discutir a relação entre Indicação geográfica (IG) e desenvolvimento regional a partir da atuação dos principais atores no Brasil. A metodologia é ancorada em pesquisa exploratória. Os principais atores envolvidos nas discussões de IG no Brasil são: MAPA, SEBRAE, INPI e Universidades. Desses atores, a metodologia de trabalho do MAPA é a que mais contribui no estímulo ao desenvolvimento regional. Palavras-chave: indicação geográfica; desenvolvimento regional; atores.

Abstract: The article seeks to discuss the relationship between Geographical Indication (GI) and regional development based on the performance of the main actors in Brazil. The methodology is anchored in exploratory research. The main actors involved in the GI discussions in Brazil are: MAPA, SEBRAE, INPI and Universities. Of these actors, MAPA's methodology is the one that contributes most to stimulating regional development.
\end{abstract}

Keywords: geographical indication; regional development; actors.

Résumé: L'article cherche à discuter de la relation entre l'Indication Géographique (IG) et le développement régional sur la base des performances des principaux acteurs au Brésil. La méthodologie est ancrée dans la recherche exploratoire. Les principaux acteurs impliqués dans les discussions sur les IG au Brésil sont: MAPA, SEBRAE, INPI et Universités. Parmi ces acteurs, la méthodologie du MAPA est celle qui contribue le plus à stimuler le développement régional.

Mots-clés: indication géographique; développement régional; acteurs.

Resumen: El artículo busca discutir la relación entre Indicación geográfica (IG) y desarrollo regional a partir de la actuación de los principales actores en Brasil. La metodología se ancla en investigación exploratoria. Los principales actores involucrados en las discusiones de IG en Brasil son: MAPA, SEBRAE, INPI y Universidades. De estos actores, la metodología de trabajo del MAPA es la que más contribuye en el estímulo al desarrollo regional.

Palabras clave: indicación geográfica; desarrollo regional; actores.

\section{INTRODUÇÃO}

Desenvolvimento regional pode ser entendido como processo de transformação econômica, social e política, cuja dinâmica é construída a partir do local e com participação ativa de seus atores, sendo imprescindível a interação entre eles. Sugere, portanto, relação com o endógeno e com a capacidade de os atores mobilizarem ativos regionais.

A partir dessa abordagem, estratégias de desenvolvimento regional podem ser estruturadas considerando seus ativos regionais, geralmente intangíveis, difíceis de serem transferidos de uma

\footnotetext{
${ }^{1}$ Universidade Regional de Blumenau (FURB), Blumenau, Santa Catarina, Brasil.
} 
região a outra e materializados principalmente em aspectos culturais e/ou naturais. Trata-se de atribuir "valor" a região diferenciando-a de outras regiões e utilizando essa diferenciação para o desenvolvimento econômico, social, ambiental e cultural.

O processo de globalização também tem estimulado essa competitividade regional. Entretanto o que se tem observado é que, embora tenha estimulado a padronização ou homogeneização de produtos e processos produtivos contribuindo para descaracterização cultural, ela também tem fortalecido discussões voltadas à importância dos produtos tradicionais, considerados diferenciados, com características específicas da região de produção (SOUZA, 2004; PECQUEUR, 2001; MAILLAT, 2002).

É justamente nesse contexto de diferenciação de produtos e serviços que emergem discussões relacionadas a contribuições que as Indicações Geográficas (IGs) oferecem ao desenvolvimento regional, a partir do reconhecimento de que produtos e serviços podem possuir forte relação com a região de produção. Amplamente utilizadas na União Europeia, principalmente em produtos agroalimentares, as IGs se constituem em instrumento ainda incipiente no Brasil, embora com grandes perspectivas de expansão.

Amparadas juridicamente pela Lei n. 9.279/1996 e reconhecidas pelo Instituto Nacional de Propriedade Industrial (INPI) classificam-se em Indicação de Procedência e Denominação de Origem. Enquanto a primeira exige notoriedade do local de origem do produto ou serviço, a segunda exige comprovação de que produto ou serviço possui qualidade ou características que se devem essencialmente à região geográfica de origem.

A partir de discussões ancoradas na relação entre indicações geográficas e desenvolvimento regional, o artigo pretende: (i) caracterizar IGs no Brasil enquanto estratégia de desenvolvimento regional; (ii) identificar os principais atores envolvidos nas discussões de IG NO Brasil e determinar seus respectivos papéis; e (iii) identificar as metodologias de trabalho utilizadas por esses atores no estímulo ao desenvolvimento regional, apontando limites e potencialidades dessas metodologias.

Além da introdução, o artigo é estruturado em quatro partes distintas. A primeira parte procura caracterizar IGs no Brasil principalmente a partir de uma abordagem jurídica e econômica e discutir sua relação com o desenvolvimento regional. Na sequência, são apresentados sucintamente os procedimentos metodológicos utilizados. A terceira parte procura apresentar e discutir os dados obtidos à luz dos objetivos destacados. Na quarta parte, são apresentadas as considerações finais.

\section{REFERENCIAL TEÓRICO}

\subsection{Indicações geográficas no Brasil}

As Indicações Geográficas (IGs) se desenvolveram de forma natural e gradativa. Esse processo se iniciou com o vinho no momento em que produtores, comerciantes e consumidores verificaram que determinados produtos apresentavam qualidades e características atribuíveis à sua origem geográfica, e consequentemente passaram a denominá-los com nome geográfico de sua procedência (KAKUTA, 2006).

A partir de uma abordagem mais conceitual, o World Intellectual Property Organization (WIPO) define IGs como "un signo utilizado para productos que tienen un origen geográfico concreto y posuen cualidades o una reputación derivadas especificamente de su lugar de origen" 
(LIMA, 2013 p. 214). Elas surgiram, portanto, para proteger produtos contra falsificações e concorrências comerciais desleais².

No Brasil, o INPI é órgão responsável por reconhecer IGs de produtos e serviços. Na definição do órgão, IGs se referem a produtos ou serviços que tenham origem geográfica específica. Seu registro reconhece reputação, qualidades e características que estão vinculadas ao local. Como resultado, elas comunicam ao mundo que certa região se especializou e tem capacidade de produzir um artigo diferenciado e de excelência (INPI, s.d.).

A legislação brasileira ${ }^{3}$ divide IGs em duas modalidades: Indicação de Procedência (IP) e Denominação de Origem (DO). De maneira objetiva, IP exige somente notoriedade 4 do local de origem dos produtos e/ou serviços. A DO exige comprovação de produto e/ou serviço, possui qualidade ou característica ${ }^{5}$ que se devem essencialmente ao local (meio geográfico) de origem, considerando-se fatores naturais como clima, solo, dentre outros, e fatores humanos como modo de fazer (BRUCH; VITROLLES; LOCATELLI, 2010; SILVA et al., 2010).

Para o consumidor distinguir produto ou serviço com IG de outro sem IG, ou mesmo de determinada marca, utiliza-se selo de controle ${ }^{6}$. Esse selo indica a associação que representa os produtores e um número de série que permite identificar origem dos produtos. Tudo isto deve estar presente e detalhado no regulamento de uso elaborado pelos produtores e aprovado pelo INPI.

A titularidade da IG é coletiva, pois é direito extensivo a todos os produtores ou prestadores de serviço que estejam na área demarcada e que explorem produtos ou serviços objeto da indicação (BRUCH; VITROLLES; LOCATELLI, 2010). Nesse sentido, tal instituto é considerado o mais social dos direitos de propriedade industrial, já que se destina a beneficiar toda a comunidade, indistintamente, não havendo um proprietário específico que possa explorar vantagens concedidas pela indicação sem proveito dos outros produtores (CERDAN; BRUCH; VITROLLES, 2010).

Segundo Giesbrecht et al. (2014), há pelo menos três setores no Brasil que se destacam na busca do reconhecimento de IG, principalmente em razão de suas especificidades, cadeia produtiva e mercado: vinhos, artesanato e café.

\footnotetext{
${ }^{2}$ Segundo Cerdan et al. (2014) foi em 1756 que ocorreu a primeira intervenção estatal para proteger uma IG. Tratava-se do vinho do Porto, que havia acabado de adquirir grande notoriedade. Essa notoriedade fez com que outros vinhos passassem a se utilizar da denominação "do Porto", provocando redução no preço do produto e, consequentemente, dos lucros dos produtores portugueses. Para tentar resolver esse problema, o Marques de Pombal determinou vários atos para proteger o vinho do Porto: agrupou produtores na Companhia dos Vinhos do Porto; definiu área de produção; efetuou descrição do produto, definiu e fixou características do vinho do Porto e suas regras de produção. Além disso, providenciou o registro por decreto do nome "Porto" para vinhos, criando a primeira Denominação de Origem Protegida.

${ }^{3}$ A legislação brasileira é relativamente sucinta em relação a IGs. Basicamente se fundamenta na Lei n. 9.279/1996, Resolução n. 075/2000 e na Instrução Normativa 25/2013.

${ }^{4}$ Notoriedade é a fama que um produto ou serviço tem em função de suas qualidades reconhecidas pelos consumidores. Ela pode estar ligada, por exemplo, a uma marca, a um produtor, ou a uma região (como é o caso da IG). Deve, portanto, estar relacionada ao reconhecimento pelo público e ter uma história com o território. No Brasil, temos como exemplo os doces de Pelotas, RS, o Guaraná de Maués, AM. Na Europa, podemos destacar o Champagne na França e o Vinho do Porto em Portugal (VELLOSO et al., 2014).

${ }^{5}$ Deve existir, portanto, fatores físicos do meio como clima, relevo, vegetação e solo que afetam significativamente a qualidade do produto. Um queijo, por exemplo, pode possuir um sabor peculiar porque é produzido a partir de leite de vacas alimentadas por uma pastagem específica de uma determinada região (VELLOSO et al., 2014, p. 103).

${ }^{6}$ A União Europeia utiliza uma classificação diferente do Brasil. Utilizam-se selos com cores diferentes que indicam se o produto é uma Indicação Geográfica Protegida- selo de cor azul, ou uma Denominação de Origem Protegidaselo cor vermelho (BRUCH.; VITROLLES; LOCATELLI, 2010).
} 
A produção de vinhos se intensificou a partir da imigração italiana, no sul do país. No final do século XX, houve grandes investimentos no setor, proporcionando o desenvolvimento tecnológico do cultivo e a inserção do produto no mercado vinícola internacional ${ }^{7}$ (GIESBRECHT et al., 2014).

O artesanato tem importância social, econômica e cultural. Com investimentos relativamente baixos, o setor utiliza matéria prima natural; promove inserção da mulher e adolescente em atividades produtivas; estimula prática do associativismo e fixa o artesão no seu local de origem (GIESBRECHT et al., 2014).

O café tem importância significativa na economia brasileira e, por muitos anos, é um dos principais produtos na pauta exportadora. Recentemente o mercado de café mundial vem se transformando, emergindo uma preferência dos consumidores por cafés especiais que valorizam aspectos como origem e qualidade (GIESBRECHT et al., 2014).

Até junho de 2018, o Brasil possuía 58 IGs nacionais reconhecidas (48 Indicações de Procedência e 10 Denominações de Origem), oito Denominações de Origem estrangeiras e 118 pedidos de reconhecimento (IP e DO) depositados no INPI (INPI, s.d.). A título de comparação, a França possui 593 IGs, Itália 420 IGs e Espanha 123 IGs.

Nos últimos anos, o que se tem observado é que o crescimento relativamente acelerado de IGs no Brasil se deve principalmente ao trabalho de atores importantes envolvidos em processos de discussão e reconhecimento de IGs no país, notadamente: MAPA, INPI, SEBRAE e Universidades.

Atores, no contexto do desenvolvimento regional e das políticas públicas, podem ser definidos como indivíduos, grupos ou organizações que possuem capacidade de influenciar, de maneira direta ou indireta, a formulação e o resultado de políticas públicas. São eles que elaboram propostas, tomam decisões e fazem intenções de transformarem em ações, contribuindo para o desenvolvimento regional a partir da elaboração e implementação de políticas públicas (SECCHI, 2011).

\subsection{Desenvolvimento regional a partir das Indicações Geográficas}

Conceitualmente desenvolvimento regional pode ser entendido como processo de desenvolvimento socialmente equitativo e ecologicamente prudente, apoiado na democratização em todas as escalas, participação ativa da cidadania na definição de seu paradigma societário, na completa soberania dos sujeitos na escolha do seu futuro (SOUZA; THEIS, 2009).

Entretanto, Siedenberg (2006) inclui mais uma variável, além da social e ecológica nesta discussão: a econômica. Segundo o autor, desenvolvimento regional associa-se a mudanças sociais e econômicas que ocorrem em determinado espaço destacando também a inter-relação dessas variáveis com outros elementos e estruturas presentes na região.

Neste contexto, Becker (2001) sugere que é necessário entender desenvolvimento regional como processo de transformações econômicas, sociais e políticas, cuja dinâmica é impressa "de dentro e por iniciativa própria" dos agentes locais.

Ao reforçar a dimensão econômica, Boisier (1996) considera que o desenvolvimento de uma região pressupõe a existência de um processo de crescimento econômico, que pode caracterizarse por alguns atributos simultaneamente: (i) crescente processo de autonomia regional, ou seja, a região definindo seu desenvolvimento; (ii) crescente movimento de inclusão social e participação

${ }^{7}$ A IG do Vale dos Vinhedos é a única brasileira reconhecida na União Europeia. 
popular; (iii) processo de conscientização em relação a preservação ambiental e manejo racional de recursos; e (iv) uma identificação da população com sua região.

Diante dessas discussões surgem as IGs como estratégia para estímulo ou fortalecimento do desenvolvimento regional. Embora a dimensão econômica- presente na agregação de valor aos produtos, aumento na produção, expansão de mercados, estímulo a atividades complementares - seja a mais destacada, existem outras dimensões que podem ser estimuladas a partir do reconhecimento de um produto com IG (PELLIN, 2016).

Para a European Commission (s.d), o reconhecimento de IG estimula dimensão social na medida em que produtores precisam se associar para solicitar reconhecimento do produto ou serviço. Nesse caso, ocorre inevitavelmente um fortalecimento dos vínculos sociais entre atores locais e destes com atores externos públicos e privados. Essa dimensão coletiva acaba fortalecendo o capital social da região, elemento importante para promoção do desenvolvimento regional.

Por estar pautado nos saberes, modo de ser e de fazer local, o reconhecimento de produtos e serviços com IG serve de apoio para preservação do patrimônio material e imaterial. Representam importante ferramenta para desenvolvimento regional ao permitir que regiões promovam produtos através da autenticidade da produção ou peculiaridades ligadas a sua história, cultura ou tradição, estabelecendo o direito reservado aos produtores estabelecidos na referida região (DULLIUS, 2009). Trata-se de uma apropriação devida e um reconhecimento legítimo aos conhecimentos tradicionais regionais (LIMA, 2013, p. 13).

Nesse sentido, se constituem em exemplos concretos de como um conhecimento tácito, que é socialmente distribuído, pode gerar importantes nichos de mercado servindo de suporte para uma competitividade territorial sustentável. Um exemplo emblemático pode ser observado na região de Midi-Pyrénées, na França, especificamente em Roquenfort. Nessa região, o conhecimento tácito distribuído permitiu que essa pequena localidade fabricasse o queijo Roquefort. Não há fábricas de queijo, mas todos da comunidade sabem como fabricar e qualquer consumidor em qualquer parte do mundo sabe que se trata de um produto caro devido à qualidade elevada (BOISIER, 2002).

Portanto IGs permitem que regiões promovam seus produtos criando valor local, beneficiando a comunidade, tornando-se ferramenta de desenvolvimento. Seu papel é ainda mais importante em áreas onde há baixos volumes de produção e escala, geralmente em função da tradicionalidade da produção. Nesse caso, busca-se agregar valor a essa tipicidade. IGs também são ferramentas para preservação da biodiversidade, conhecimento regional e recursos naturais (KAKUTA, 2006).

Outro ponto importante se relaciona com a capacidade de as IGs promoverem preservação e valorização do patrimônio biológico e cultural. Trata-se, por exemplo, de valorizar a biodiversidade. Como muitas IGs estão baseadas em recursos genéticos locais, sua preservação acaba sendo fundamental, uma questão de sobrevivência (EUROPEAN COMMISSION, s.d). Há alguns exemplos emblemáticos de IGs brasileiras baseadas em recursos genéticos locais e que valorizam sua biodiversidade. O vinho dos Vales da Uva Goethe é produzido a partir de uma variedade de uva que estava desaparecendo na região (variedade Goethe), e o regulamento de uso da produção de carne do Pampa Gaúcho da Campanha Meridional ${ }^{8}$ prevê uma exploração consciente dos campos do Pampa Gaúcho para a alimentação do gado bovino (CERDAN et al., 2014).

\footnotetext{
${ }^{8}$ A ONG internacional "BidrLife"- um movimento de conservação da natureza e dos pássaros- tem demonstrado interesse em se associar aos produtores da Carne do Pampa Gaúcho da Campanha Meridional nas suas ações de conservação do Bioma Pampa (CERDAN et al., 2014).
} 
Finalmente, IGs também podem desempenhar papel importante na proteção, gestão ou criação de paisagens, já que seus produtos carregam a imagem do território onde são produzidos - vinhedos da região de Bordeaux na França, vinhedos da Serra Gaúcha, campos verdes do Pampa Gaúcho, ou seja, permite uma relação possível entre produção e preservação ambiental (CERDAN et al., 2014).

Fortalecendo essas discussões, Gollo e Castro (2008) sintetizam possíveis repercussões na área geográfica e no contexto mercadológico geradas a partir do reconhecimento de produto ou serviço com IG:

Quadro 1- Repercussões na Área Geográfica e no Mercado Geradas por uma IG

\begin{tabular}{|c|c|}
\hline Repercussões na área geográfica & Repercussões de caráter mercadológico \\
\hline $\begin{array}{l}\text { - Traz satisfação ao produtor, que vê seus produtos } \\
\text { comercializados com a IG que corresponde a seu } \\
\text { local de trabalho, valorizando sua propriedade. } \\
\text { - Estimula investimentos na própria zona de } \\
\text { produção-melhoriastecnológicas nos processos } \\
\text { produtivos etc. } \\
\text { - Aumenta a participação do produtor no ciclo } \\
\text { de comercialização dos produtos e estimula a } \\
\text { elevação do seu nível técnico. } \\
\text { - Estimula a melhoria qualitativa dos produtos, } \\
\text { já que estes são submetidos a controles de } \\
\text { produção e de elaboração. } \\
\text { - Contribui para a preservação das características } \\
\text { e da tipicidade dos produtos, que se constituem } \\
\text { num patrimônio de cada região / país. } \\
\text { à prosibilita desenvolver atividades paralelas } \\
\text { exemplo, o turismo. }\end{array}$ & $\begin{array}{l}\text { - Aumenta o valor agregado dos produtos e/ou } \\
\text { gera maior facilidade de colocação no mercado. } \\
\text { Os produtos ficam menos sujeitos à concorrência } \\
\text { com outros produtos de preço e qualidades } \\
\text { inferiores. } \\
\text { - Melhora e torna mais estável a demanda do } \\
\text { produto, pois cria uma confiança do consumidor } \\
\text { que, sob a etiqueta da IG, sabe que vai encontrar } \\
\text { um produto de qualidade e com características } \\
\text { regionais. } \\
\text { - Permite ao consumidor identificar perfeitamente } \\
\text { o produto dentre outros, inclusive de preços } \\
\text { inferiores. } \\
\text { - Oportuniza mecanismos legais contra fraudes } \\
\text { e usurpações, facilitando a ação contra o uso } \\
\text { indevido da IG. }\end{array}$ \\
\hline
\end{tabular}

Fonte: Adaptado de Gollo e Castro (2008).

Entretanto "o reconhecimento de uma IG, por si só, não garante a priori sucesso comercial" (CERDAN et al., 2014 p. 41) e, por consequência, desenvolvimento da região. Muitas variáveis precisam ser consideradas: característica do produto e cadeia produtiva, mercado, nível de estruturação dos produtores (capital social), canais de distribuição, dentre tantas outras.

\section{PROCEDIMENTOS METOdOLÓGICOS}

Metodologicamente trata-se de pesquisa exploratória e estudo de caso por se propor a analisar o papel e metodologia de trabalho dos principais atores que estimulam discussões relacionas a IGs no Brasil. Na etapa exploratória, foram realizadas pesquisas bibliográficas e documentais que abordam tanto temas tradicionais, como emergentes relacionados a IGs e sua relação com o desenvolvimento regional.

\footnotetext{
${ }^{9}$ Há inclusive limitações das IGs como instrumentos de diferenciação. Se por um lado há IGs que conquistaram espaço e reconhecimento nos mercados de singularidades (Vale dos Vinhedos para vinhos, Cerrado Mineiro para café, Paraty para cachaça; por outro existem situações em que os produtores se quer mencionam esse tipo de diferenciação (Vale dos Sinos para couro acabado, Vale do Submédio São Francisco para uva e manga) (NIEDERLE, 2014, p. 252).
} 
Paralelamente à realização da pesquisa bibliográfica e documental, o pesquisador participou como observador em reuniões de IGs promovidas ou apoiadas pelos principais atores que discutem o tema no Brasil. Também foram aplicadas entrevistas semiestruturadas aos principais atores buscando identificar o papel desses atores nas discussões, bem como metodologias de trabalho utilizadas para estímulo ao desenvolvimento regional.

$\mathrm{Na}$ etapa de sistematização e análise dos dados, a pesquisa utilizou abordagem qualitativa em função da relação dinâmica que existe entre realidade e sujeitos envolvidos. O tratamento e análise dos dados obtidos foi efetuado através de tratamento na forma de categorias analíticas/ operativas. De acordo com Gomes (1996), categoria se refere a conceito que abrange elementos ou aspectos com características comuns ou que se relacionam entre si. São empregadas para se estabelecer classificações, e trabalhar com elas significa agrupar elementos, ideias ou expressões em torno de um conceito.

\section{APRESENTAÇÃO E DISCUSSÃO DOS RESULTADOS}

Entre os atores nacionais mais importantes e atuantes que realizam ou estimulam ações voltadas a IGs, destacam-se: Ministério da Agricultura, Pecuária e Abastecimento (MAPA), Instituto Nacional de Propriedade Industrial (INPI), Serviço Brasileiro de Apoio às Micro e Pequenas Empresas (SEBRAE) e universidades, públicas e privadas.

A partir da identificação dos atores, procurou-se verificar seus respectivos papéis na arena de discussões de IGs no Brasil e metodologias de trabalho utilizadas no estímulo ao desenvolvimento regional, apontando limites e potencialidades dessas metodologias.

\section{- Ministério da Agricultura, Pecuária e Abastecimento (MAPA)}

O MAPA é responsável pela gestão das políticas públicas de estímulo à agropecuária, pelo fomento do agronegócio e pela regulação e normatização de serviços vinculados ao setor. Através da Secretaria de Desenvolvimento Agropecuário e Cooperativismo (SDC), criou a Coordenação de Incentivo à Indicação Geográfica de Produtos Agropecuários $(\mathrm{CIG})^{10}$ para planejamento, fomento, coordenação, supervisão e avaliação de atividades, programas e ações relacionadas a IGs de produtos agropecuários. Suas ações envolvem apoio financeiro para estruturação de projetos de IG, capacitação e organização de produtores.

Em 2005, o MAPA estabeleceu convênio com o Instituto Nacional de Propriedade Industrial (INPI) e se consolidou como principal entidade para planejar, fomentar, coordenar atividades e programas relacionados a IGs de produtos agropecuários no país. Para auxiliar na expansão das IGs no Brasil, a CIG desenvolveu ações importantes ${ }^{11}$ como um roteiro que busca explicar, de maneira clara e objetiva, as principais etapas na elaboração do processo de reconhecimento: (i) organização dos produtores; (ii) levantamento histórico-cultural; (iii) elaboração do regulamento técnico de produção; (iv) criação do Conselho Regulador da IG; e (v) apresentação de projeto ao INPI (GLASS; CASTRO, 2009).

\footnotetext{
${ }^{10}$ Criada através da Portaria n 85 de 10 de abril de 2006.

${ }^{11}$ O MAPA também realizou uma parceria com a Universidade Federal de Santa Catarina (UFSC) para oferecer um curso na modalidade EaD em Propriedade Intelectual e inovação no Agronegócio que, em seu módulo II, trata especificamente das IGs e suas contribuições para o desenvolvimento regional. O curso procura capacitar agentes fomentadores e técnicos para discutir as IGs como estratégia de desenvolvimento local.
} 
Vinculada ao MAPA, está a Empresa Brasileira de Pesquisa Agropecuária (EMBRAPA), que possui, entre suas principais subdivisões, a Embrapa Uva e Vinho com função de desenvolver ações de pesquisa com uva, vinho, maçã e outras frutas de clima temperado (EMPRAPA, s.d.).

O desenvolvimento de IGs de vinhos no Brasil passou a ser incentivado pela Embrapa Uva e Vinho no início dos anos 1990. O primeiro trabalho com o setor privado foi desenvolvido com um grupo de vitivinicultores que formaram, em 1995, a Associação dos Produtores de Vinhos do Vale dos Vinhedos (APROVALE) (TONIETTO; ZANUS, s.d.) e que culminou com reconhecimento da IG do Vale dos Vinhedos, em 2002. Nos últimos anos, a Embrapa Uva e Vinho teve participação decisiva no reconhecimento de cinco IGs de vinhos: IP Pinto Bandeira, IP Altos Montes, IP Região de Monte Belo, IP Farroupilha e IP do Vale dos Vinhedos, todas no Rio Grande do Sul. Além disso, está apoiando projetos em desenvolvimento que buscam o reconhecimento da IP Submédio São Francisco, IP Campanha Gaúcha e IG para vinhos de altitude na serra catarinense.

As ações desenvolvidas pela Embrapa Uva e Vinho nesses projetos possibilitaram realização de diagnósticos de potencialidades das regiões, identificação de melhores climas e solos para produção, delimitação de área de produção para a IG, variedades que se adaptam melhor à região produtora e definição de padrões de qualidade das uvas e vinhos de cada IG. Como resultado dessas ações, verificou-se significativa melhoria na qualidade dos produtos, uma competitividade diferencial para os produtos com IG e maior desenvolvimento regional na área delimitada de produção. Além disso, estimulou desenvolvimento de atividades complementares nas regiões como enoturismo ${ }^{12}$ e enogastronomia (TONIETTO; ZANUS, s.d.).

A partir de 2013, o MAPA tem utilizado uma metodologia de trabalho com IGs, procurando investir em ações integradas para organizar toda cadeia produtiva. A nova metodologia foi inspirada em proposta de trabalho estruturada conjuntamente pela Organização das Nações Unidas para a Agricultura e Alimentação (FAO) e Rede Internacional de Pesquisa sobre Indicações Geográficas (SINER-IG), instituição financiada pela União Europeia (PELLIN, 2016).

Essa nova metodologia busca a promoção do desenvolvimento regional sustentável através das IGs e considera os atores locais protagonistas desse processo de desenvolvimento. O MAPA adaptou a metodologia à realidade brasileira, dividindo-a em três etapas: (i) prospecção, (ii) mobilização e caracterização e (iii) organização e promoção.

A prospecção não se limita apenas a identificar na região produtos agroalimentares com potencial para reconhecimento, mas também a mapear atores (em seus mais diversos níveis) que poderiam auxiliar no reconhecimento da IG e se beneficiar direta ou indiretamente desse reconhecimento. A partir disso, o objetivo é construir uma rede de trabalho envolvendo esses atores. Trata-se de estimular o desenvolvimento da região a partir de seus ativos territoriais e estimular o capital social, enquanto procura identificar e articular atores locais do território e resguardando os ativos, sustentando-os no tempo e espaço.

A etapa de mobilização e caracterização envolve principalmente a sensibilização dos atores em torno de sua responsabilidade coletiva nas discussões relacionadas à produção e comercialização dos produtos e/ou serviços reconhecidos. É nessa etapa que produtores são capacitados para cooperar entre si, e não apenas competir. É a etapa em que frequentemente surgem conflitos, e o processo de governança territorial (legítimo e representativo) passa a ser ponto nevrálgico. Interesses coletivos devem estar acima de interesses individuais, e isso

\footnotetext{
12 Principal atividade complementar que pode ser estimulada a partir do reconhecimento de IGs vitivinícolas.
} 
é particularmente um grande desafio diante do pensamento empresarial, individualista e da cultura política predominante.

A etapa de organização e promoção é uma etapa que ocorre geralmente após o reconhecimento do produto e/ou serviço e, por isso, tem importância significativa para a sustentabilidade do projeto. No Brasil, a grande maioria das ações de apoio a IGs preocupam-se excessivamente com o processo de reconhecimento em detrimento da etapa pós-reconhecimento. Na metodologia do MAPA, essa etapa procura desenvolver estratégia para inserir o produto e/ou serviço no mercado através de ações efetivas de marketing ou mesmo a construção de canais de distribuição. Trata-se de dar sustentabilidade, principalmente econômica, para a IG.

\section{- Instituto Nacional de Propriedade Industrial (INPI)}

Criado em 1970, o INPI, vinculado ao Ministério do Desenvolvimento, Indústria e Comércio Exterior (MDIC), é autarquia federal responsável pelo aperfeiçoamento, disseminação e gestão do sistema brasileiro de concessão e garantia de direitos de propriedade intelectual para a indústria. Entre os serviços do INPI, está o registro das IGs. O setor que trata dessas questões é a Diretoria de Contratos, Indicações Geográficas e Registros (DICIG), que atua na deliberação sobre registros. Além disso, a DICIG participa de atividades articuladas entre o INPI e órgãos parceiros, empresas privadas e outras entidades, promovendo divulgação e maior participação de brasileiros nos sistemas de proteção da propriedade intelectual (INPI, s.d.).

O INPI desempenha papel importante na orientação de produtores e empresários, ou mesmo associações já constituídas quanto a elaboração e encaminhamento dos projetos de solicitação de registro para IG. Essas orientações são fundamentais para diminuir tempo de espera no reconhecimento da IG e até mesmo para verificar viabilidade de solicitação da IG para determinado produto e/ou serviço.

Frequentemente técnicos do INPI percorrem o Brasil participando de eventos relacionados a IGs. Trata-se de estratégia importante para torná-las conhecidas de produtores e consumidores e fomentar surgimento de novas experiências. Em muitos casos são abordadas questões técnicas importantes relacionadas à legislação e tramitação de processos no instituto.

Outra atividade importante desenvolvida pelo órgão é elaboração e publicação de materiais de divulgação relacionados a IGs, em parceria com outras entidades, principalmente com SEBRAE. São publicações que contêm orientações para desenvolvimento e encaminhamento de projetos de reconhecimento de IGs junto ao INPI e orientações para diagnosticar potencialidades. O objetivo é popularizar IGs e estimular surgimento de novos produtos e/ou serviços com potencial de reconhecimento.

A instituição também tem papel importante na qualificação discente através do Programa de Pós-Graduação em Propriedade Intelectual e Inovação. O programa oferece curso de Stricto Sensu em nível de mestrado profissionalizante e, desde 2013, doutorado. Ambos os cursos são gratuitos e credenciados pela Coordenação de Aperfeiçoamento de Pessoal de Nível Superior do Ministério da Educação (CAPES/MEC).

\section{- Serviço Brasileiro de Apoio às Micro e Pequenas Empresas (SEBRAE)}

O SEBRAE é entidade privada sem fins lucrativos que atua na indústria, comércio, serviços e agronegócio. É agente de capacitação e promoção do desenvolvimento, criado para dar apoio 
aos pequenos negócios. Desde 1972, trabalha para estimular o empreendedorismo e possibilitar a competitividade e a sustentabilidade dos empreendimentos de micro e pequeno porte. Com foco no estímulo ao empreendedorismo e no desenvolvimento sustentável dos pequenos negócios, o SEBRAE atua também no acesso a novas tecnologias e inovação (SEBRAE, s.d.).

Recentemente tem se incorporado em vários projetos de apoio a IGs no Brasil. Segundo Giesbrecht (2012), até junho de 2012, o SEBRAE nacional participou diretamente de vinte e cinco projetos de IGs reconhecidas pelo INPI (19 Indicações de Procedência e seis Denominações de Origem), beneficiando cerca de dez mil produtores. Em muitos casos, suas ações acabam sendo decisivas, principalmente no apoio financeiro para elaboração de projetos encaminhados ao INPI.

A metodologia de trabalho do SEBRAE divide-se em duas fases: (i) sensibilização e (ii) capacitação, ambas direcionadas a empresas e produtores rurais. A fase de sensibilização envolve publicações, vinculação de trabalhos na mídia, realização de eventos e oferece uma contribuição importante para popularizar o conceito de IG e estimular o interesse de produtores e empresas em reconhecer produtos com potencial para IG. A segunda etapa de trabalho é capacitação de empresas e produtores rurais. Nesta etapa ocorre apoio do SEBRAE na elaboração dos projetos de IG que posteriormente são encaminhados ao INPI para reconhecimento do produto. A partir de 2012, esse apoio é oferecido principalmente através do SEBRAETec ${ }^{13}$ (GIESBRECHT, 2012).

Embora a instituição desempenhe papel importante no fortalecimento de IGs no Brasil, sua metodologia de trabalho possui algumas limitações. Geralmente suas ações, em formato de consultorias e assessorias, muitas vezes com prazos determinados, acabam priorizando a elaboração e depósito do projeto de reconhecimento da $\mid G$ no $|N|^{14}$. Outro ponto relaciona-se ao fato de que o excessivo foco no mercado acaba privilegiando a dimensão econômica das IGs, enxergando nelas apenas um negócio.

Em função disso, preocupações relacionadas ao fortalecimento de capital social na região através da sensibilização e mobilização dos atores locais, estímulo a processos de governança representativos e legítimos, participação de atores da cadeia com relação indireta com a IG, entre outras questões, acabam relegadas a segundo plano e podem comprometer a sustentabilidade da IG no médio e longo prazo.

A predominância excessiva da dimensão econômica em detrimento de outras dimensões como a cultural, ambiental e social sugere que a metodologia de trabalho do SEBRAE não possui preocupação em considerar IGs como ferramenta para estímulo e promoção do desenvolvimento regional no território objeto de reconhecimento.

\section{- Universidades públicas e privadas}

Embora universidades não formulem políticas públicas, oferecem apoio importante no desenvolvimento de IGs no país, principalmente através de projetos de pesquisa desenvolvidos no âmbito de programas stricto sensu. Geralmente, por estarem inseridas nas regiões de abrangência dos projetos e possuírem pesquisadores de várias áreas (facilitando abordagens interdisciplinares), têm conseguido oferecer contribuições importantes para fortalecimento das

\footnotetext{
${ }^{13}$ É um programa do SEBRAE que permite à micro e pequenas empresas e ao produtor rural ter acesso subsidiado a serviços de inovação e tecnologia, melhorando os processos de produção e inovação, tornando-os mais competitivos no mercado.

${ }^{14}$ Assim como previa a metodologia antiga do MAPA.
} 
IGs. Em muitos casos, atuam desde o início das discussões até o estágio de pós-reconhecimento.

A Universidade Federal de Santa Catarina (UFSC) tem desempenhado papel de destaque no estímulo e apoio a projetos de $\mathrm{IG}^{15}$, inclusive em outros estados. Através de parceria com Ministério da Agricultura, Pecuária e Abastecimento (MAPA) oferece curso na modalidade à distância de Propriedade Intelectual e Inovação no Agronegócio que possui módulo específico sobre IG.

Além da UFSC, há outros exemplos emblemáticos de como universidades contribuíram para o reconhecimento de IGs. A Universidade de Caxias do Sul (UCS) teve papel decisivo na delimitação geográfica e elaboração do regulamento de uso na IG Vale dos Vinhedos. A Universidade Federal do Rio de Janeiro (UFRJ) participou ativamente na organização da cadeia produtiva da cachaça na IG Cachaça de Paraty. A Universidade do Extremo Sul Catarinense (UNESC) vem apoiando produtores da IG do Vales da Uva Goethe, mesmo após o reconhecimento da IG do produto, através da elaboração de planos de negócio para inserção do produto com IG no mercado (PELLIN, 2016).

Por fim, é importante lembrar que mesmo universidades que não possuem parcerias ou convênios específicos com projetos de IG oferecem contribuições importantes para fortalecimento de discussões. Isso ocorre através do interesse científico demonstrado pelo tema e do estímulo ao desenvolvimento de projetos de pesquisa ${ }^{16}$ que abordam temáticas relacionadas à IGs e suas contribuições para desenvolvimento das regiões onde estão inseridas.

A partir dessas discussões, as metodologias utilizadas pelos principais atores e sua contribuição para o desenvolvimento regional podem ser observadas no quadro síntese a seguir:

Quadro 2 - Síntese de metodologias utilizadas e relação do desenvolvimento regional

\begin{tabular}{|c|c|c|}
\hline Ator & Descrição sucinta da metodologia & Contribuições da metodologia para DR \\
\hline MAPA & $\begin{array}{l}\text { 1. Atores locais são protagonistas no pro- } \\
\text { cesso. } \\
\text { 2. Metodologia ancorada em várias etapas } \\
\text { (prospecção, mobilização e caracterização } \\
\text { e organização e promoção). } \\
\text { 3. Procura trabalhar em toda cadeia pro- } \\
\text { dutiva (da produção a comercialização). } \\
\text { 4. Metodologia prevê apoio continuo a } \\
\text { processos de IG. } \\
\text { 5. Apoio técnico para elaboração de proje- } \\
\text { tos de reconhecimento de IG. } \\
\text { 6. Capacitação de atores locais }\end{array}$ & $\begin{array}{l}\text { 1. Estímulo e fortalecimento do capital } \\
\text { social local. } \\
\text { 2. Fortalecimento de toda cadeia produ- } \\
\text { tiva do setor, gerando emprego e renda } \\
\text { local. } \\
\text { 3. Estímulo a governança territorial local. } \\
\text { 4. Inserção de produtores e produtos no } \\
\text { mercado, gerando emprego e renda local. } \\
\text { 5. Estímulo ao desenvolvimento de ativi- } \\
\text { dades complementares (turismo). } \\
\text { 6. Preocupação com sustentabilidade so- } \\
\text { cial, ambiental, cultural e econômica da IG. }\end{array}$ \\
\hline
\end{tabular}

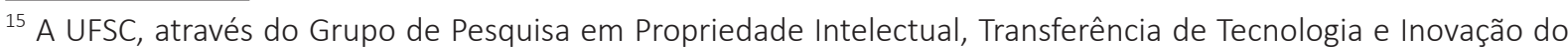
Programa de Pós-Graduação em Direito, efetuou recentemente um estudo para identificar possíveis produtos com potencial para solicitação de IG em várias regiões de Santa Catarina.

${ }^{16}$ Em Santa Catarina, por exemplo, é possível destacar a atuação de algumas universidades catarinenses: Universidade Regional de Blumenau (FURB) através do Núcleo de Políticas Públicas do Programa de Pós Graduação em Desenvolvimento Regional, Universidade do Extremo Sul de Santa Catarina (UNESC) através do projeto de pesquisa Propriedade Intelectual, Desenvolvimento e Inovação e a Universidade do Contestado (UnC) através do projeto de pesquisa Signos Distintivos Territoriais e Indicação Geográfica.
} 


\begin{tabular}{|c|c|c|}
\hline Ator & Descrição sucinta da metodologia & Contribuições da metodologia para DR \\
\hline INPI & $\begin{array}{l}\text { 1. Socialização do tema de IG no país. } \\
\text { 2. Orientação técnica a produtores, em- } \\
\text { presários e associações em relação a IG } \\
\text { (potencialidades e limites). } \\
\text { 3. Elaboração e distribuição de material } \\
\text { informativo sobre IGs. } \\
\text { 4. Qualificação de profissionais através de } \\
\text { cursos stricto sensu. }\end{array}$ & $\begin{array}{l}\text { 1. Estímulo ao recońhecimento de IGs no } \\
\text { Brasil. } \\
\text { 2. Fortalecimento das discussões de IG } \\
\text { enquanto estratégia de desenvolvimento } \\
\text { regional. }\end{array}$ \\
\hline SEBRAE & $\begin{array}{l}\text { 1. Metodologia ancorada em duas etapas: } \\
\text { sensibilização e capacitação. } \\
\text { 2. Capilaridade em suas ações. } \\
\text { 3. Apoio técnico na elaboração de projetos } \\
\text { de reconhecimento de IGs. } \\
\text { 4. Elaboração e distribuição de material } \\
\text { informativo sobre IGs. } \\
\text { 5.Disponibilidade de recursos financeiros } \\
\text { para projetos de IG. } \\
\text { 6. Capacitação de atores locais. }\end{array}$ & $\begin{array}{l}\text { 1. Atua próximo a região e produtores } \\
\text { (capilaridade da organização). } \\
\text { 2. Expertise na elaboração de planos de } \\
\text { negócios, fundamental na etapa pós re- } \\
\text { conhecimento (vitalidade da IG). }\end{array}$ \\
\hline $\begin{array}{l}\text { Universidades } \\
\text { (públicas e } \\
\text { privadas) }\end{array}$ & $\begin{array}{l}\text { 1. Apoio técnico para elaboração de proje- } \\
\text { tos de reconhecimento de IG. } \\
\text { 2. Capacitação de atores locais. } \\
\text { 3. Apoio na realização de pesquisas labo- } \\
\text { ratoriais. }\end{array}$ & $\begin{array}{l}\text { 1. Possibilita abordagem multidisciplinar } \\
\text { do desenvolvimento regional. } \\
\text { 2. Geralmente atua próximo a região e } \\
\text { produtores, o que garante fácil inserção } \\
\text { nos projetos de discussão e reconheci- } \\
\text { mento de IG. }\end{array}$ \\
\hline
\end{tabular}

Fonte: Elaborado pelo autor.

Por fim, é importante lembrar que, embora a literatura e até mesmo experiências emblemáticas no mundo reconheçam IGs como estratégia de desenvolvimento regional, não há garantias de que isto efetivamente ocorra.

Particularmente no Brasil, onde a discussão de IGs enquanto estratégia de desenvolvimento regional ocorre em estágio ainda embrionário, muitos desafios ainda precisam ser superados, principalmente de natureza mercadológica. Entre esses desafios, destacam-se: (i) o total desconhecimento da IG por parte dos consumidores, (ii) preços mais elevados desses produtos em relação aos demais produtos, em função de seu sistema produtivo possuir custos de produção mais elevados, e (iii) baixa escala de produção, dadas as especificidades da produção.

O enfrentamento desses desafios será possível com a implementação de políticas públicas de estímulo a IGs, principalmente na fase de pós-reconhecimento. Contudo é ponto fundamental que essas políticas públicas considerem o protagonismo dos produtores locais como fator determinante para promover ou estimular o desenvolvimento regional.

\section{CONSIDERAÇÕES FINAIS}

Notadamente é na dimensão econômica que se esperam as maiores contribuições das IGs para o desenvolvimento regional. Para produtores, elas podem agregar valor ao produto e/ou serviço, aumentar vendas através da conquista de novos mercados ou mesmo expansão de mercados já existentes. Para a região, podem proporcionar maior visibilidade e impulsionar atividades complementares como o turismo, que pode fortalecer a economia através da geração de emprego e renda local. 
Entretanto estímulos à dimensão social, cultural e ambiental do desenvolvimento também podem ser observados. Fortalecimento do capital social, preservação do patrimônio material e imaterial e preservação da biodiversidade regional são alguns exemplos que, inclusive, aproximam IGs do desenvolvimento regional sustentável.

Em função de sua extensão territorial, miscigenação cultural e diversidade climática, um número considerável de produtos e serviços possuem potencial para reconhecimento de IG em várias regiões do país. Para transformar esse potencial em realidade, é fundamental a atuação de atores como MAPA, INPI, SEBRAE e Universidades. Cada qual com suas especificidades, contribuições e limitações.

A metodologia de trabalho do SEBRAE é pautada principalmente na sensibilização e capacitação dos atores. Considera o depósito do processo no INPI como produto final do trabalho. Tem, portanto, um caráter mais técnico desenvolvido através de consultorias e assessorias, processo do qual, nem sempre, produtores são protagonistas.

Outro ponto a ser considerado na metodologia do SEBRAE é o excessivo foco no mercado, priorizando a dimensão econômica nas discussões, em detrimento das outras dimensões do desenvolvimento (ambientais, sociais e culturais). Ocorre, portanto, uma preocupação excessiva com a sustentabilidade econômica dos empreendimentos, e não necessariamente com a promoção do desenvolvimento regional.

Como ponto positivo em relação aos demais atores, é importante destacar a capilaridade da instituição. Essa capilaridade permite ao SEBRAE estar presente em todo o país, atuando de maneira mais próxima aos projetos de IG. Outro ponto é sua "expertise" na elaboração de planos de negócio que pode ser fundamental na etapa pós-reconhecimento de IG, quanto produtores precisam inserir seus produtos no mercado.

O INPI tem a função de reconhecer IGs, através de uma análise técnica e jurídica dos processos submetidos a ele. Portanto não se pode esperar do órgão uma atuação mais presente junto aos produtores. Todavia a instituição tem desempenhado papel importante tanto na orientação de produtores, quanto na elaboração dos processos de solicitação de reconhecimento. Frequentemente técnicos da instituição participam de eventos em todo o país estimulando discussões e orientando produtores e instituições em relação a questões técnicas e jurídicas relacionadas a IGs. Possui papel importante na popularização do tema e, recentemente, tem se esforçado para agilizar a análise de processos de reconhecimento de IGs.

Universidades, públicas e privadas, possuem papel importante no processo. Por estarem próximas ou mesmo fazerem parte da região da IG, têm condições de contribuir de maneira mais efetiva nas discussões, inclusive a partir de uma abordagem interdisciplinar, tão importante para entender e estimular as várias dimensões do desenvolvimento regional.

Entretanto é o MAPA o ator protagonista das IGs no Brasil. Atuando mais incisivamente desde 2005 nas IGs agroalimentares, a instituição tem desempenhado papel fundamental para consolidação das IGs como estratégia de desenvolvimento regional. A partir de 2010, a instituição apostou em uma nova metodologia de trabalho, inspirada na metodologia de trabalho da FAO e SINER-IG, que busca estimular IGs promovendo o desenvolvimento regional a partir do protagonismo dos atores locais.

Ao analisar a metodologia de trabalho do MAPA, é possível identificar uma relação umbilical entre ela e os princípios do desenvolvimento regional a partir de pelo menos sete aspectos emblemáticos: (i) a região procura se desenvolver a partir de suas potencialidades e produtores 
são protagonistas do processo de desenvolvimento; (ii) há estímulo ao desenvolvimento do capital social da região enquanto produtores e atores (em seus mais diversos níveis) discutem coletivamente ações de desenvolvimento para o território; (iii) Produtores passam a cooperar entre si, e não apenas a competir (superando a visão economicista geralmente predominante); (iv) atores que se beneficiam indiretamente do reconhecimento da IG também são envolvidos no projeto, ampliando a relação de beneficiados; ( $v$ ) atividades complementares, que podem se beneficiar com o reconhecimento da IG, são estimuladas favorecendo o desenvolvimento territorial da região, e não apenas dos produtores e seus empreendimentos; (vi) a metodologia não se limita a estimular a dimensão econômica. Dimensões culturais, ambientais e sociais também estão presentes nas discussões; e (vii) a metodologia estimula um sentimento de "pertencimento" do produtor com o território. O produtor passa a ter orgulho em produzir determinado produto e/ou serviço, de determinada maneira e em determinada região.

\section{REFERÊNCIAS}

BECKER, B. K. Revisão das políticas de ocupação da Amazônia: é possível identificar modelos para projetar cenários? Parcerias Estratégicas, Brasília, n. 12, p. 135-59, set. 2001.

BOISIER, S. Sociedad del conocimiento, conocimiento social y gestión territorial. In BECKER, D. F.; BANDEIRA, P. S. (Org.). Respostas regionais aos desafios da globalização. Santa Cruz do Sul, RS: EDUNISC, 2002. 308p.

BOISIER, S. Modernidad y territorio. Santiago de Chile: ILPES, 1996.

BRUCH, K. L.; VITROLLES, D.; LOCATELLI, L. Estudo de caso: IP Vale dos Vinhedos, IP Paraty e IP Vale do Submédio São Francisco. In: CERDAN, C. M.; BRUCH, K. L.; SILVA, A. L. (Org.). Curso de propriedade intelectual e inovação no agronegócio. Florianópolis, SC: SEaD/UFSC/FAPEU, 2010. Módulo II-Indicação Geográfica. MAPA.

CERDAN, C.; BRUCH, K.; VITROLLES, D. Gestão e controle pós-reconhecimento das indicações geográficas. In: CERDAN, C. M.; BRUCH, K. L.; SILVA, A. L. (Org.). Curso de propriedade intelectual e inovação no agronegócio. 2. ed. Brasília: MAPA; Florianópolis, SC: SEaD/UFSC/FAPEU, 2010. Módulo II, indicação geográfica / Ministério da Agricultura, Pecuária e Abastecimento. 376p.

CERDAN, C. M. T.; BRUCH, K. L.; SILVA, A, L.; COPETTI, M.; FÁVERO, K. C.; LOCATELLI, L. Indicação geográfica de produtos agropecuários: importância histórica e atual. In: PIMENTEL, L. O. (Org.). Curso de propriedade intelectual e inovação no agronegócio. 4. ed. Florianópolis, SC: FUNJAB, 2014. Módulo II - Indicação Geográfica. Ministério da Agricultura, Pecuária e Abastecimento. 415p.

DULLIUS, P. R. Indicações geográficas e desenvolvimento territorial: as experiências do Rio Grande do Sul. 2009. Dissertação (Mestrado em Extensão Rural)- Universidade Federal de Santa Maria (UFSM)- Santa Maria, RS, 2009.

EMPRAPA. Embrapa Uva e Vinho. [s.d.]. Disponível em: https://www.embrapa.br/uva-e-vinho. Acesso em: 18 abr. 2014.

EUROPEAN COMMISSION. Workshops on Geographical Indications - Development and use of specific instruments to market origin-based agricultural products in African - ACP countries Brussels - Belgium. [s.d]. Disponível em: http://ec.europa.eu/agriculture/events/2014/gi-workshops/training-brochure_en.pdf. Acesso em: 25 mar. 2015.

GIESBRECT, H. O. Indicação Geográfica como ferramenta para o aumento da competitividade de produtores, empresas e região. In: Workshop Catarinense de Indicações Geográficas. 2012. Trabalho não publicado. 
GIESBRECHT, H. O.; MINAS, R. B. A.; GONÇALVES, M. F. W.; SCHWANKE, F. H. Indicações geográficas brasileiras. Brasília: SEBRAE/INPI, 2014. 264p.

GLASS, R. F.; CASTRO, A. M. G. As Indicações Geográficas como estratégia mercadológica para vinhos. Texto para discussão 35. Brasília, DF: EMBRAPA, 2009.

GOLLO, S. S.; CASTRO, A. W. V. Indicações geográficas no Brasil: as indicações de procedências já outorgadas e as áreas e produtos com potencial de certificação. In: CONGRESSO DA SOCIEDADE BRASILEIRA DE ECONOMIA, ADMINISTRAÇÃO E SOCIOLOGIA RURAL, 46., 2008, Rio Branco, AC. Anais [...]. Rio Branco, AC: SOBER, 2008.

GOMES, R. A análise de dados em pesquisa qualitativa. In: MINAYO, M. C. S. (Org.). Pesquisa social: teoria, método e criatividade. 5. ed. Petrópolis, RJ: Vozes, 1996.

INPI. Resolução n. 75, de 28 de novembro de 2000, do Instituto Nacional da Propriedade Intelectual. Estabelece as condições para o registro das indicações geográficas. Disponível em: http://www.inpi.gov. br/menu-servicos/indicacao-geografica/guia-basico-de-indicacao-geografica. Acesso em: 23 jun. 2018.

KAKUTA, S. M. Indicações geográficas: guia de respostas. Porto Alegre, RS: SEBRAE/RS, 2006.

LIMA, G. S. N. M. S. Indicações Geográficas e desenvolvimento territorial sustentável. In. RUSSO, S. L.; SILVA, G. F. (Org.). Capacite - exemplos de inovação tecnológica. São Cristóvão, SE: Editora da UFS, 2013. 240p.

MAILLAT, D. Globalização, meio inovador e sistemas territoriais de inovação. Interações - Revista Internacional de Desenvolvimento Local, Campo Grande, MS, v. 3 n. 4, p. 9-13, mar 2002.

NIEDERLE, P. A. Desenvolvimento, instituições e mercados agroalimentares: os usos das indicações geográficas. In: DALLABRIDA, V. R. (Org.). Desenvolvimento territorial: políticas públicas brasileiras, experiências internacionais e a indicação geográfica como referência. São Paulo: LiberArts, 2014. p. 237-63.

PECQUEUR, B. Qualité e développement territorial: I' hyphotèse du pannier de biens et de services territorialisés. Economie Rurale, Paris, n. 261, p. 37-49, jan./fev. 2001.

PELLIN, V. Indicação geográfica, políticas públicas e desenvolvimento territorial sustentável: uma análise a partir do processo de reconhecimento da IG para chope e cerveja artesanal da região de Blumenau (SC), em sua arena pré-decisional. 2016. Tese (Doutorado em Desenvolvimento Regional)- Universidade Regional de Blumenau (FURB), Blumenau, SC, 2016.

SEBRAE. Especialistas em pequenos negócios. [s.d.]. Disponível em: http://www.sebrae.com.br/sites/ PortalSebrae/canais_adicionais/conheca_quemsomos. Acesso em: 15 mar. 2014.

SECCHI, Leonardo. Políticas públicas: conceitos, esquemas de análise, casos práticos. São Paulo: Cengage Learning, 2011.

SIEDENBERG, D. R. Desenvolvimento regional. In: SIEDENBERG, D. R. (Org.). Dicionário desenvolvimento regional. Santa Cruz do Sul, RS: EDUNISC, 2006. 168p.

SILVA, A. L.; CERDAN, C.; VELLOSO, C. Q.; VITROLLES, D. Delimitação geográfica de área: homem, história e natureza. In: CERDAN, C. M.; BRUCH, K. L.; SILVA, A. L. Curso de propriedade intelectual e inovação no agronegócio. Florianópolis, SC: SEaD/UFSC/FAPEU, 2010. Módulo II - Indicação Geográfica. MAPA.

SOUZA, C. M. M.; THEIS, I. M. Desenvolvimento regional: abordagens contemporâneas. Blumenau, SC: Edifurb, 2009. 
SOUZA, N. J. Globalização, crescimento e pobreza. A visão do Banco Mundial sobre os efeitos da globalização (Resenha de livro). Análise Econômica, Porto Alegre, RS, ano 22, n. 42, p. 279-84, set. 2004.

TONIETTO, J.; ZANUS, M. C. Indicações Geográficas. Ageitec - Agência Embrapa de Informação Tecnológica. [s.d.]. Disponível em: http://www.agencia.cnptia.embrapa.br/gestor/uva_para_processamento/arvore/ CONT000g5kvmfxb02wx5ok01edq5slp81qk5.html. Acesso em: 15 maio 2015.

VELLOSO, C. Q.; BRUCH, K. L.; CADORI, A.P.; LOCATELLI, L. Identificação dos produtos potenciais e organização dos produtores. In: PIMENTEL, L. O. (Org.). Curso de propriedade intelectual e inovação no agronegócio. 4. ed. Florianópolis, SC: FUNJAB, 2014. Módulo II - Indicação Geográfica. Ministério da Agricultura, Pecuária e Abastecimento. 415 p.

\section{Sobre o autor:}

Valdinho Pellin: Mestre e Doutor em Desenvolvimento Regional pelo Programa de Pós-Graduação em Desenvolvimento Regional da Universidade Regional de Blumenau (PPGDR/FURB). Graduado em Economia. E-mail: prof.pellin@tpa.com.br 